\title{
A Case Report of Thyroid Gland Metastasis in Small Cell Lung Cancer
}

\author{
Shiqiang Yang
}

\begin{abstract}
Thyroid metastasis of small cell lung cancer is rare in clinic, and few cases have been reported so far. We reported one case of 61-year-old Chinese male patient who presented with a progressive enlargement of mass in the right thyroid gland for 1 month. It was confirmed later to be originating from a small cell lung cancer. Then the patient was given chemoradiotherapy, but still died 6 months later. Although thyroid gland metastasis in lung cancer is rare in clinic, it should not be misdiagnosed. The treatment of thyroid metastasis of small cell lung cancer is mainly chemoradiotherapy; long-term survival of thyroid metastasis remained worse.
\end{abstract}

Keywords: Thyroid gland metastasis; Small cell lung cancer; Neoplasm metastasis

\section{Introduction}

Primary bronchogenic carcinoma is one of the most common malignant tumors. The incidence and mortality of lung cancer all over the world are rising, especially in developing countries such as China [1]. According to the cancer statistics in China 2015 [2], the incidence and mortality of lung cancer were $17.09 \%$ and $21.68 \%$, respectively. It has a propensity to metastasize to any organ. It often metastasizes to the brain, bone, liver, lung, adrenal gland, etc. The metastases of lung cancer to the thyroid gland are rare [3]. Of the four types of lung cancer causing thyroid gland metastasis, adenocarcinomas are the commonest followed by squamous and large cell carcinomas. The metastasis of small cell lung cancer to the thyroid gland is rarely reported [4]. The purpose of this report is to present thyroid gland metastasis of a small cell lung cancer, as the first site of metastasis, originally misdiagnosed as thyroid carcinoma, confirmed to be originating from a small cell lung cancer.

\section{Case Report}

A 61-year-old Chinese male was admitted to our hospital for

Manuscript submitted March 5, 2018, accepted March 22, 2018

Xintai Hospital Affiliated to Taishan Medical University, No. 1329 Xinfu Road, Xintai, Tai’an City, China. Email: sdzbysq@163.com

doi: https://doi.org/10.14740/jmc3031w progressive right thyroid enlargement for 1 month. The patient had been a smoker of 20 cigarettes per day for over 40 years, sometimes complained of cough and expectoration but did not complain other symptoms related to lung cancer. Thyroid ultrasound examination showed there to be a hypoechoic nodule with a size of $4.1 \times 2.6 \mathrm{~cm}$ (Fig. 1). Therefore, we first diagnosed it as a primary thyroid carcinoma. A fine needle aspiration (FNA) revealed clusters of malignant epithelial. Immunohistochemistry showed thyroid transcription factor-1 ( TTF-1) $(+)$, synaptophysin (Syn ) (+), actin (-), S-100 (-), P63 (-), epithelial membrane antigen (EMA) (-), cytokeratin 20 (CK 20 ) (-) (Fig. 2). Then, we did the chest computed tomography (CT) examination; CT scan revealed a shadow in the right upper lobe, with a size of approximately $5.4 \times 6.3 \mathrm{~cm}$ (Fig. 3). The diagnosis of small cell lung cancer was followed by fiberoptic bronchoscopy. Then chemotherapy protocol of etoposide 100 $\mathrm{mg} / \mathrm{m}^{2} \mathrm{D} 1-3$ and cisplatin $75 \mathrm{mg} / \mathrm{m}^{2} \mathrm{D} 1$ was performed. After two cycles of chemotherapy, the external radiotherapy was given. After 6 months, the patient died of respiratory failure.

\section{Discussion}

The thyroid gland is at risk for tumor metastases from distant sites because of its rich vascular supply [5]. Metastases from other malignant tumors to the thyroid gland are an uncommon clinical presentation. In autopsy, primary lung cancer is a com-

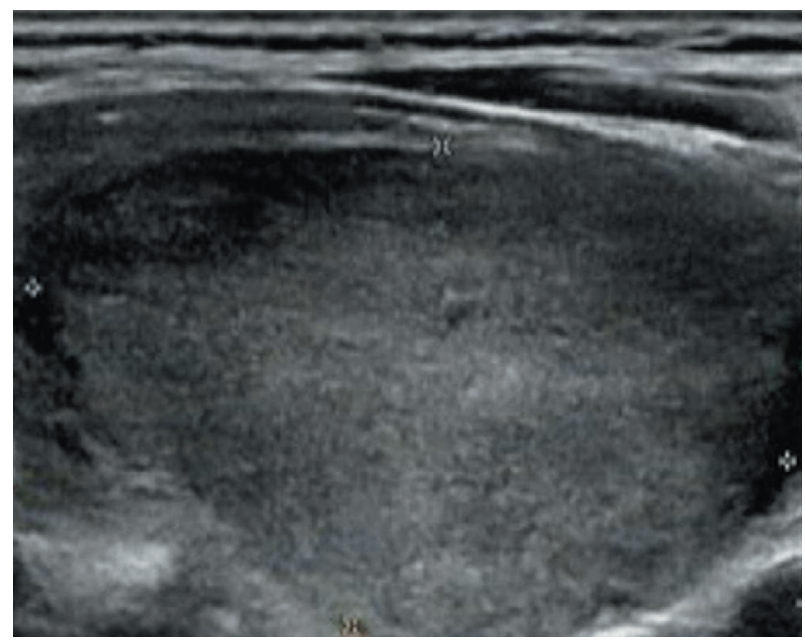

Figure 1. Thyroid ultrasound examination showed a hypoechoic nodule with the size of $4.1 \times 2.6 \mathrm{~cm}$. 


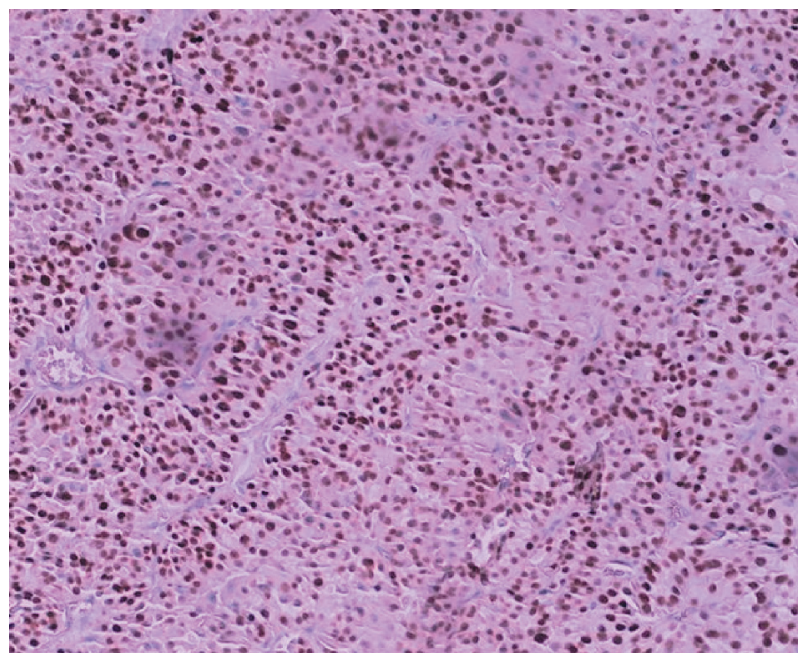

Figure 2. Immunohistochemistry showed thyroid transcription factor-1 $($ TTF-1) $(+)(\times 100)$.

mon part of thyroid gland metastases. In clinical treatment, renal cell carcinoma is the most common primary site, followed by breast cancer and gastrointestinal malignancies. Of the lung cancer known to metastasize to the thyroid, non-small cell lung cancer is the most common type. There are only a few reported cases of thyroid metastases in small cell lung cancer $[6,7]$. The diagnosis of small cell lung cancer sometimes is made from metastatic lesions.

We report a case of thyroid metastasis as the first symptom. Small cell carcinoma was determined by FNA biopsy and the thyroid metastasis of small cell lung cancer was confirmed by chest CT examination. The pathology can be confirmed by FNA of the thyroid gland. Studies have shown that the sensitivity rate of thyroid FNA biopsy to the diagnosis of thyroid metastases is $83 \%$ (range 65 to $98 \%$ ) [8]. Chung et al estimated that thyroid gland FNA biopsy provide the correct diagnosis in $73.7 \%$ of all patients [5]. FNA biopsy of thyroid gland is difficult to differentiate between primary thyroid carcinoma and highly differentiated metastatic carcinoma.

Thyroid metastasis of small cell lung cancer is not recommended for thyroidectomy. The clinical treatment recommended chemotherapy with cisplatin and etoposide, or chemotherapy and radiotherapy. Osawa et al [4] reported a case of small cell lung cancer underwent chemotherapy consisting of cisplatin and etoposide, followed by prophylactic cranial irradiation. Four years later, a thyroid metastasis was diagnosed then followed by thyroidectomy. After adjuvant chemotherapy, the patient has been disease-free for over 1 year. After the occurrence of thyroid metastasis, it thought to indicate poor prognosis. With the improvement of the treatment modalities, the survival of the patients was increased to 9 and 18 months. Calzolari et al reported that the survival of single metastases of thyroid were superior to multiple metastases [9].

With the increasing application of imaging technology, such as positron emission tomography, FNA biopsy of thyroid, and the longer survival of tumor patients, thyroid metastatic diseases will be more frequent.

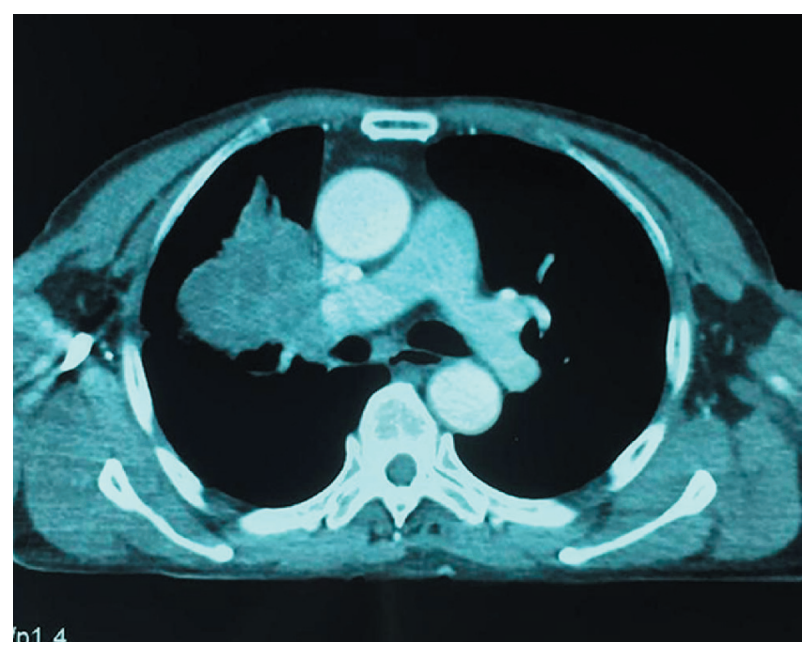

Figure 3. Chest computed tomography (CT) examination scan revealed a shadow in the right upper lobe, with a size of approximately $5.4 \times 6.3 \mathrm{~cm}$.

In view of our clinical case report, we suggest that the metastases of small cell lung cancer to the thyroid gland are rare. The clinical diagnosis requires FNA biopsy of the thyroid gland. The primary tumor was small cell lung cancer then etoposide and cisplatin treatment protocol was start, and external radiotherapy was given. The patient died 6 months after the diagnosis, shorter than expected. It is necessary to optimize treatment protocol.

\section{Conclusions}

Although thyroid gland metastasis in small cell lung cancer is extremely rare, a potential metastasis of small cell lung cancer should not be ignored in the diagnosis of thyroid tumor. However long-term survival of thyroid metastasis remained worse. The treatment protocol needs to be improved.

\section{Financial Support}

Funded by the scientific research department of the Xintai People's Hospital

\section{References}

1. Jemal A, Bray F, Center MM, Ferlay J, Ward E, Forman D. Global cancer statistics. CA Cancer J Clin. 2011;61(2):69-90.

2. Chen W, Zheng R, Baade PD, Zhang S, Zeng H, Bray F, Jemal A, et al. Cancer statistics in China, 2015. CA Cancer J Clin. 2016;66(2):115-132.

3. Hulikal N, Naru RR, Gangasani R, Nandyala R, Pai A, Meenakshisundaram M. A case of synchronous isolated thyroid metastasis from a primary lung cancer presenting as thyroid primary: Diagnostic challenge! Lung India. 
2016;33(3):326-329.

4. Osawa M, Takigawa N, Kiura K, Ichimura K, Matsuoka J, Hotta K, Tabata M, et al. Isolated metastasis of lung cancer to the thyroid gland. Lung Cancer. 2007;58(1):156158.

5. Chung AY, Tran TB, Brumund KT, Weisman RA, Bouvet M. Metastases to the thyroid: a review of the literature from the last decade. Thyroid. 2012;22(3):258-268.

6. Katsenos S, Archondakis S, Vaias M, Skoulikaris N. Thyroid gland metastasis from small cell lung cancer: an unusual site of metastatic spread. J Thorac Dis. 2013;5(2):E21-24.

7. Ozgu ES, Gen R, Ilvan A, Ozge C, Polat A, Vayisoglu Y.
Small cell lung cancer with metastasis to the thyroid in a patient with toxic multinodular goiter. J Craniofac Surg. 2012;23(6):e614-615.

8. Gharib H, Papini E, Paschke R, Duick DS, Valcavi R, Hegedus L, Vitti P, et al. American Association of Clinical Endocrinologists, Associazione Medici Endocrinologi, and EuropeanThyroid Association Medical Guidelines for clinical practice for the diagnosis and management of thyroid nodules. Endocr Pract. 2010;16(Suppl 1):1-43.

9. Calzolari F, Sartori PV, Talarico C, Parmeggiani D, Beretta E, Pezzullo L, Bovo G, et al. Surgical treatment of intrathyroid metastases: preliminary results of a multicentric study. Anticancer Res. 2008;28(5B):2885-2888. 